En la siguiente escena, la Crucifixión (fig. 2) el modelado del cuerpo de Cristo y las partes a destacar de ropajes y figuras, se resaltan por medio de la luz, consiguiéndose con el claroscuro mayor dramatismo para la escena. La figura de san Juan, de espaldas, con una actitud de pies y manos nada sosegada evoca cierto desasosiego de las composiciones grunwaldianas.

La Resurrección (fig. 3), con los efectos de luz precisos para modelar a los soldados del primer término, vuelve a ser una composición de proporciones y sensibilidad miguelangelesca, con cierto gusto decorativo en los relieves del sepulcro y en las guarniciones de las armaduras.

Sin duda la escena más atractiva es el Noli me tangere (fig. 4). En ella contrasta el ligero, armónico y lineal jardín típico del último renacimiento, con las voluminosas figuras, singularmente la de la Magdalena. Cristo como jardinero con su azada, se le aparece a su discípula predilecta (San Marcos 16,9 y San Juan 14-18). La Magdalena, con corpulentísimo cuerpo y una cabeza, en relación con él, pequeña, se arrodilla ante él, teniendo próximo a ella el simbólico frasco de perfume. Su peinado a base de bucles recogidos por finas trenzas los hallamos en Goltzius hacia el año 1570, fecha que coincide con la del tocado de la Magdalena en la escena de la Venida del Espiritu Santo, en este mismo retablo. En esta última tabla, el concepto de amaneramiento de las figuras, el movimiento de las mismas y los efectos de luz están acordes con lo pintado en estos últimos años del siglo Xvi.

Finalmente en la tabla de la Coronación de la Virgen (fig. 6) desaparecen los efectos de luz siendo el dinamismo de los ángeles y el del manto de la Virgen los protagonistas de la composición, preludiando las Inmaculadas barrocas.

Si nos fijamos en su dependencia de Leyden y Goltzius, tal vez habríamos de pensar en un pintor flamenco, con estancia en Italia, y posteriormente trabajando en Toledo. Como de su estilo sólo hemos localizado una Piedad, (fig. 7), en colección privada madrileña $(83 \times 82 \mathrm{~cm}$ ), con atribución a Correa, cuyos modelos coinciden con los del retablo de Durham, tal vez se trate de un pintor itinerante o de paso por Toledo, al que, de momento, podríamos denominar como Maestro del retablo de Durham.

Isabel Mateo Gómez Dpt. H. ${ }^{\mathrm{a}}$ del Arte, CSIC

\title{
EL TEMPLO PARROQUIAL DE LA CAMPANA (SEVILLA): LAS REFORMAS DEL SIGLO XVIII
}

Los orígenes de la iglesia parroquial de La Campana debemos situarlos acaso en la primera mitad del siglo Xv cuando se fundó una ermita dedicada a la Virgen de la Consolación, en torno a la cual se apiñaban un conjunto de casas habitadas por trabajadores de los campos del entorno ${ }^{1}$. Ya en la segunda mitad de la misma centuria aparece mencionado el edificio como «la iglesia de La Campana” ', evidenciándose que constituía ya una auténtica fábrica, con sus presbíteros y sus rentas, no dependiendo, pues, del priorato de ermitas.

\footnotetext{
1 Manuel Serrano afirmó que la vieja ermita originaria estaba dedicada a la Virgen del Carmen; sin embargo, desconocemos de dónde extrajo la información y más bien pensamos que fue un error de su autor. Serrano y Ortega, Manuel: Guía de los monumentos históricos y artísticos de los pueblos de la provincia de Sevilla, Sevilla, 1911, p. 59.

2 González Jiménez, Manuel: Catálogo de documentación medieval del Archivo Municipal de Carmona (1475-1504), t. II, Sevilla, Diputación Provincial, 1981, p. 239.
} 
De la primitiva ermita son muy pocas las referencias de que disponemos, aunque sí podemos precisar que era muy pequeña y que estuvo sirviendo al culto hasta finales del siglo XVI ${ }^{3}$. Las obras de la iglesia que sustituyó a la vieja ermita comenzaron como es sabido en 1565, prolongándose las labores hasta cerca de 1630, debido a la penuria económica en que se encontraba la fábrica.

En las obras hemos podido distinguir tres fases en las cuales estuvieron a cargo distintos maestros, a saber: la primera comprendida entre 1565 y 1575 , en cuyo periodo estuvo al frente de las obras el maestro sevillano Calaeta, consistiendo el proyecto inicial en una iglesia "de tres capillas cubiertas de bóvedas» ${ }^{4}$. Sin embargo, Calaeta murió dejando la iglesia "sacada de cimientos" y levantada una vara del suelo ${ }^{5}$.

La segunda fase abarcó nada menos que desde 1575 a 1595, es decir, dos décadas, durante las cuales estuvo dirigida por el carmonense Cristóbal González «El Viejo» quien modificó el proyecto inicial que preveía una cubierta abovedada, sustituyéndolo por un artesonado de madera que resultaba más barato ${ }^{6}$. Pese a que su trabajo se prolongó durante veinte años, Cristóbal González tan sólo levantó los muros del templo sin llegar a cubrirlos lo cual se debió nuevamente a la precariedad de la fábrica que hacía que a cada momento hubiese que suspender la construcción por falta de recursos económicos.

Y, finalmente, entre 1595 y 1630 transcurrió la tercera fase en la construcción, comenzando con una visita que hizo a la iglesia el Maestro Mayor de Obras del Arzobispado, Vermundo Resta, el cual redactó un expediente el 29 de octubre de 1595, en el que aprobó la idea que previamente tenía la fábrica de cubrir el templo con un artesonado ${ }^{7}$. Las obras aprobadas por Resta fueron llevadas a cabo por el albañil Alonso Moreno y por los carpinteros Juan Ibáñez y Francisco Hernández Ibáñez, todos ellos vecinos de la vecina localidad de Fuentes de Andalucía. El artesonado de la nave debió estar acabado para abril de 1600, pues, en esa fecha el concejo de la villa acordó traer a los Maestros Mayores del arzobispado de Sevilla para que la examinasen ${ }^{8}$. Sin embargo, todavía se iba a retrasar más de 25 años la finalización de la capilla mayor debido, como en otras ocasiones, a la penuria económica (Fig. 8).

El edificio quedó finalmente concluido con los siguientes elementos, a saber: una nave principal y dos muy pequeñas cubiertas todas ellas con vigas de pino, un presbiterio abovedado y en el crucero una cúpula de mampostería sobre pechinas. La extensión total del recinto fue de 11 varas de ancho por 26,5 de ancho según nos consta por un expediente redactado por Pedro de Silva en 1766, antes de ser ampliadas las naves laterales ${ }^{9}$. En cuanto a la iluminación del templo

\footnotetext{
3 Algunos testimonios al respecto indican que era de una nave y de tres tapias de alto y que apenas si tenía cimientos. Declaración del carpintero Pedro Suárez, La Campana, 7 de julio de 1595. Archivo Municipal de La Campana (en adelante AMLC), leg. 382.

4 Así lo declaró Cristóbal González: «...Porque antes estaba tratado iba la obra fundada para hacerla de tres capillas y cubrirla de bóveda en que se gastará mucho más que ahora se gastará con la nueva orden que se ha dado en cubrirla de madera...». AMLC, leg. 382.

5 Ibidem.

6 Se trataba de un artista que laboraba dentro de los gustos mudéjares pues conocemos algunas obras suyas en Carmona como la portada de la iglesia de San Blas de Carmona, realizada en 1567 por un precio de 16.500 maravedises. Villa Nogales, Fernando de la, y Esteban Mira Caballos: Documentos inéditos para la historia del arte en la provincia de Sevilla (s. XVI al XVIII), Sevilla, Caja San Fernando, 1993, p. 25.

7 El expediente de 1595 ha sido publicado íntegramente. Hernández Díaz, José; Antonio Sancho Corbacho y Francisco Collantes de Terán: Catálogo Arqueológico y Artístico de la Provincia de Sevilla, t. II, Sevilla, 1943, pp. 36-42. Sobre este brillante arquitecto del manierismo sevillano puede verse la obra de Marín Fidalgo, Ana: Vermundo Resta, Sevilla, Arte Hispalense, 1988.

8 Cabildo del 9 de abril de 1600. AMLC. Actas Capitulares, lib. I, s/f.

9 Memorial de Pedro de Silva sobre las obras de la iglesia de La Campana, Sevilla, 23 de agosto de 1766. AGAS, Justicia 653.
} 
se procuraba gracias a tres ventanas con vidrieras y por lo demás había tres puertas de acceso, dos en los colaterales y otra principal a los pies ${ }^{10}$.

Esta explicación sobre el templo antiguo la vamos a completar con una relación que hizo de él el vicario general del arzobispado de Sevilla en una visita realizada a la parroquia en 1659 y en la que lo describía en los siguientes términos:

«la capilla mayor es de bóveda y la demás iglesia formada de la nave principal y las dos colaterales y son medias y es de ladrillo y hormigón y los techos de muy buen enmaderado, tiene tres puertas y sobre la principal está el campanario con dos campanas de golpe, una mayor que la otra...." ${ }^{11}$.

En las décadas posteriores se debió tomar la decisión de enmascarar el artesonado de la nave principal con una bóveda de medio cañón con lunetos, pues, aunque no tenemos constancia documental de estos trabajos, la decoración del intradós de los arcos torales, de las pechinas de la cúpula y de las claves de las bóvedas de las naves son motivos típicos del barroco sevillano de la primera mitad del siglo XVII ${ }^{12}$.

Por lo demás, entre la segunda mitad del siglo xvII y la primera del XVIII se hicieron capillas en los muros de las capillas laterales, algunas de una gran riqueza, aunque por desgracia la mayor parte de ellas desaparecieron en esta última centuria con la ampliación de las naves colaterales. Las capillas del muro de la epístola eran la llamada "capilla Nueva», aún hoy existente y la única que era de la fábrica ${ }^{13}$, la de Santa Ana que era una de las más suntuosas de la iglesia ${ }^{14}$, la del Carmen y la de San Cristóbal, mientras que en el muro del evangelio se situaban la de la Veracruz, la de la Virgen del Rosario, la de San José y la de la familia Muñoz donde se veneraba un Jesús Nazareno que todavía hoy se conserva en la parroquia.

\section{Las grandes reformas del siglo XVIII}

Como es bien sabido en la segunda mitad del siglo xviII se generó en Sevilla un movimiento arquitectónico sin precedentes en todo el reino de Sevilla motivado por factores de diversa índole, a saber: la riqueza de la diócesis sevillana, los numerosos desastres naturales que ocurrieron desde mediados de la centuria, y, finalmente, el gran aumento que experimentó la población y que trajo consigo la necesidad de ampliar numerosos templos parroquiales ${ }^{15}$. En este marco florecieron artífices de gran talento como Diego Antonio Díaz, los Figueroa y Pedro de Silva entre otros.

En este sentido, la villa de La Campana no fue una excepción pues en su templo se llevaron a cabo en el siglo xviI importantes reformas que determinaron su fisonomía actual, hasta tal punto que casi se puede afirmar que el edificio que hoy podemos contemplar, salvo algunos elementos de la fachada principal, del crucero y de la nave central, es obra dieciochesca. El factor que más influyó en este caso concreto a la hora de realizar las reformas fue el excepcional creci-

10 Concierto con Diego Hernández Ibáñez, carpintero vecino de Fuentes. AMLC, leg. 382.

11 Archivo General del Arzobispado de Sevilla (en adelante AGAS), Visitas, leg. 1445.

12 Hernández Díaz: Catálogo arqueológico y artístico, t. II, p. 24.

13 Esta capilla, con su bonita cúpula, se conserva en la actualidad y está situada en la cabecera de la nave de la epístola y fue labrada, como luego veremos, por Antonio de Figueroa en 1760.

14 Según una declaración de Pedro de Silva, esta capilla «está toda estofada y con un retablo muy lucido, que además de esto tiene todas sus paredes una chapadura de jaspe muy especial y la acompaña una colgadura de damasco». Memorial de Pedro de Silva, Sevilla, 23 de agosto de 1766. AGAS, justicia 653.

15 Falcón Márquez, Teodoro: Pedro de Silva, Sevilla, Arte Hispalense, 1979, pp. 16-19. 
miento demográfico que experimentó la localidad en esta centuria superior sin duda a la mayoría de las localidades sevillanas ${ }^{16}$.

Ya, en 1755, nos consta que estaba construida la sacristía nueva, situada en el testero de la iglesia, y más concretamente en el antiguo cementerio parroquial, ocupando también un pasadizo que había detrás de la iglesia, que el concejo había cedido ese mismo año, con la intención de que ésta quedase con la suficiente «amplitud y decencia». De esta sacristía, que por supuesto se ha conservado hasta nuestros días, contamos con una minuciosa descripción, redactada en 1766 por Pedro de Silva y que transcribimos parcialmente a continuación:

«...No ha muchos años que con licencia de este tribunal se construyó nueva sacristía (parece que a costa de la fábrica) muy primorosa a espaldas del altar mayor que comprende en su largo todo el dicho testero y colaterales, la cual tiene su cuarto aparte para taca, confesarse los sacerdotes que está a mano izquierda y, al lado, tiene su patio de luces y lugares comunes todo con mucha comodidad, nuevo y bien ejecutado..." ${ }^{17}$.

Por desgracia desconocemos el maestro que la diseñó aunque por su airoso estilo y por la combinación de elementos barrocos y clásicos debemos relacionarlas con el quehacer de Antonio de Figueroa, quien, como veremos a continuación, trabajó ampliamente en esta iglesia a lo largo de la centuria decimoctava.

En cuanto a las tareas de ampliación del templo parroquial, nos consta el trabajo de dos Maestros Mayores de Fábricas del Arzobispado: Pedro de Silva y el ya citado Antonio de Figueroa, lo cual es muy importante ya que hasta la fecha se hacía responsable de ellas exclusivamente al segundo ${ }^{18}$. Nuevamente, pues, hemos de atribuir a Pedro de Silva obras tradicionalmente adscritas a los Figueroa ${ }^{19}$. Como es bien sabido Pedro de Silva ostentó desde 1756 el cargo de maestro mayor de obras del Arzobispado de Sevilla, puesto que ocupó durante 26 años, participando así en muchos de los trabajos que se realizaron durante esas fechas en la diócesis hispalense ${ }^{20}$.

Efectivamente, la documentación que hemos hallado en el Archivo General del Arzobispado de Sevilla es muy importante ya que se pone de manifiesto lo que hizo cada maestro. Así, hemos podido comprobar que fue el maestro Silva el responsable de la ampliación de las dos naves laterales y de la bella portada del lado del Evangelio, mientras que Antonio de Figueroa se encargó de labrar la llamada "Capilla Nueva» y la portada principal, así como de ampliar el presbiterio. Igualmente, y como veremos a continuación, ha quedado claro que durante los dos años que Antonio de Figueroa residió en la villa fue para construir la "Capilla Nueva" y su bóveda, y, muy probablemente la pequeña cúpula de la cabecera de la nave de la epístola, no volviendo a

16 La población casi se cuatriplicó en poco más de 40 años, al pasar de 1.324 habitantes en 1750 a 4.588 en 1791 . Padrones poblacionales. AMLC, leg. 91-103. Libro de curatos del Arzobispado de Sevilla, Sevilla, Imprenta del Arzobispado, 1791, f. 95

17 Memorial de Pedro de Silva, Sevilla, 23 de agosto de 1766. AGAS, Justicia 653.

18 Hernández Díaz en el Catálogo tan sólo hacía mención a Antonio de Figueroa a quien consideraba autor de las trazas de la nueva iglesia, afirmación que como hemos dicho es errónea. Hernández Díaz: Catálogo Arqueológico y Artísti$c o$, p. 42. En obras posteriores los autores se han limitado a repetir lo que se afirmó en el Catálogo Arqueológico y Artístico. Morales, Alfredo J., y otros: Inventario Artístico de Sevilla y su provincia, t. I. Madrid, Ministerio de Cultura, 1982 , pp. 91-92. Morales, Alfredo J., y otros: Guía Artística de Sevilla y su provincia, Sevilla, Excma. Diputación Provincial, 1989, p. 356. Además, en el trabajo ya citado del profesor Teodoro Falcón dedicado a Pedro de Silva no se hace mención alguna a los trabajos de éste en la iglesia de Santa María la Blanca de La Campana. Falcón Márquez: Pedro de Silva.

19 Concretamente, en fechas muy recientes documentamos las trazas de la capilla del Sagrario de la iglesia de San Pedro de Carmona como obra de Pedro de Silva, cuando históricamente se consideraba una de las obras cumbres de Ambrosio de Figueroa. Este último participó en la construcción pero sin embargo, la traza, pese a ser similar a la de la iglesia sevillana de San Luis de los Franceses diseñada por Leonardo de Figueroa, son adscribibles a Silva. Véase Mira Caballos, Esteban, y Fernando de la Villa Nogales: "En torno al arquitecto sevillano Pedro de Silva», Atrio n. ${ }^{\circ}$ 8-9, Sevilla, 1996.

20 Falcón Márquez: Pedro de Silva, pp. 27-29. 
trabajar en la iglesia hasta finales de siglo cuando trazó la portada principal. Es interesante observar la exuberante decoración barroca que muestran las cúpulas de la llamada "capilla Nueva" y de la cabecera de la nave de la epístola que contrasta con el frío estilo neoclásico que, como analizaremos en páginas posteriores, imprimió a la portada principal varias décadas después. Sin duda, la rica ornamentación de yeserías de las pechinas y del intradós de la bóveda de la cabecera de la epístola así como la línea alabeada de las molduras del tambor muestran una relación evidente con la labor realizada por Ambrosio de Figueroa en los sagrarios de San Pedro de Carmona y Santa Bárbara de Ecija ${ }^{21}$.

En cuanto a las obras de ampliación del templo nos consta documentalmente que el 23 de agosto de 1766 Pedro de Silva emitió un informe, tras una visita realizada al templo, en el que ponía de manifiesto la necesidad que tenía la parroquia de tales reformas, lo cual «ni puede ser por la cabeza ni tampoco por los pies..." no habiendo otro medio "que el hacer naves colaterales» ${ }^{22}$. Por fortuna, en la edificación inicial había dos pequeñas naves laterales por lo que se pudieron aprovechar los arcos formeros, reduciéndose bastante los costes de ampliación. El propio Pedro de Silva escribió lo siguiente en relación a la existencia de los arcos formeros:

«...Queda dicho que en sus rompimientos no puede haber el más leve perjuicio por hallarse ejecutada la principal operación que es la de los referidos arcos, lo cual vale mucho que esté así..." 23 .

Gracias a ello la valoración de los costes que hizo Silva se redujo a la modesta cantidad 95.000 reales de vellón bastante menos que lo que importó, por ejemplo, ampliar las naves laterales de un templo de similares dimensiones como era el de San Pedro de Carmona ${ }^{24}$.

Sin embargo, fue en otro memorial, redactado por el maestro Silva, en 1778, cuando se señalaron las condiciones que se debían observar en la ampliación de la iglesia, concretándose incluso el modo que debían observar en la cimentación ${ }^{25}$. Igualmente, se especificó que las naves laterales debían estar cubiertas por bóvedas de arista enlucidas con cal, definiendo, finalmente, como debían ser las portadas laterales.

Este último aspecto nos interesa bastante ya que hemos podido documentar la portada del lado del evangelio como obra de Pedro de Silva, realizada en $1778{ }^{26}$. Sin duda esta portada, realizada en piedra blanca de Estepa ${ }^{27}$, puede considerarse un buen ejemplo del barroco sevi-

21 No en vano la capilla del Sagrario de la parroquia de Santa Bárbara de Ecija estuvo atribuida a Antonio de Figueroa hasta que finalmente se documentó como obra de Ambrosio. Pese a todo se sabe que Antonio de Figueroa intervino en su construcción y que la visitó en varias ocasiones. Véase a Arenillas, Juan Antonio: Ambrosio de Figueroa, Sevilla, Arte Hispalense, 1993, pp. 55-56 y 62- 64.

22 Memorial de Pedro de Silva, Sevilla, 23 de agosto de 1766. AGAS, Justicia 653.

23 Ibidem.

24 Las obras de ampliación de las naves de la iglesia de San Pedro de Carmona fueron comenzadas por el albañil Esteban de Paredes bajo la dirección de Pedro de Silva en 1760 y dos años después, es decir, en 1762, se estimaba que hacían falta para acabarlas nada menos que 102.000 reales de vellón. Villanogales: En torno a Pedro Silva, p. 244 .

25 Sobre este particular se decía lo siguiente: ...«Llene sus cimientos de buenos hormigones, terciados a tres y a dos, bien infusos, ligados y pisados...». Memorial de Pedro de Silva, Sevilla primero de febrero de 1778. Memorial de Pedro de Silva, Sevilla, primero de febrero de 1778. AGAS, Justicia 653.

26 Hemos de resaltar la importancia de este dato, ya que esta labor estaba atribuida a Antonio de Figueroa. Hernández Díaz: Catálogo Arqueológico y Artístico, t. II, p. 26.

27 En el proyecto de Silva se preveía la posibilidad de hacerla de piedra si en las cercanías a la localidad hubiese unas canteras. Concretamente en su memorial expuso lo siguiente: "Las dos portadas que hay que hacer duda el maestro mayor si el ladrillo que hay en aquella tierra tendrá o no calidad para poderla ejecutar con la fortaleza debida las cuales han de guardar en si la orden dórica y por si acaso sobreviene que en dos leguas se hallase cría buena de piedra... se puede ejecutar así por no tener mucho más costo y ser más firme para la injuria de los temporales...». Memorial de Pedro de Silva, Sevilla, primero de febrero de 1778. AGAS, Justicia 653. Pese a que las canteras de piedra se encontraban en Estepa a mucho más de dos leguas de distancia la fábrica decidió que se labrase de piedra. 
llano de la centuria decimoctava. Estructuralmente está formada por un vano adintelado enmarcado por pilastras, completándose el conjunto con un remate mixtilineo que rodea el emblema del apóstol San Pedro. Pese a que las pilastras toscanas presentan diversos juegos de molduras rectas y curvas contrasta su sobriedad con la riqueza de molduras y los juegos mixtilíneos del remate, sin duda, de un vibrante barroquismo. Sin embargo, pese a su barroca ornamentación ya se advierten algunos elementos propios de la etapa neoclásica como por ejemplo el dintel y los triglifos 28 (Fig. 10).

Por otro lado, desde 1784, Miguel José de Barrios, presbítero de la parroquia, tenía la idea de completar el arreglo de su templo, por un lado, con la ampliación y solado del presbítero y, por el otro, con una portada principal que estuviese más acorde con la grandeza del nuevo templo. Así, el 15 de agosto de 1784 se concertó con el cantero ecijano Francisco Blázquez ${ }^{29}$ para que solara las 42 varas del presbiterio con jaspe encarnado de Estepa, todo lo cual tuvo un coste total de 9.876 reales de vellón ${ }^{30}$. Previamente, se había obligado con el alarife de La Campana, Juan de la Vega, para que labrase la bóveda de entierro del presbiterio ${ }^{31}$. Por lo demás, sabemos que hacia junio de 1785 estaba acabado el presbiterio ya que en esa fecha visitó y aprobó las obras el Maestro mayor del Arzobispado Antonio de Figueroa.

Con respecto a la portada principal sabemos que ya en 1784 el maestro José Alvarez recomendó su reparación ya que, según informó, estaba «imperfecta» y «desentonaba mucho» con la iglesia recién reparada. En 1792, visitó de nuevo la iglesia Antonio de Figueroa, reconociendo las obras ejecutadas, y describiendo su suntuosidad con las siguientes palabras:

«A instancias de la dicha fábrica de dicha iglesia con el cual conocimiento la fue reconociendo así por lo exterior como por lo interior y vio ser un templo de los más suntuosos que se hallan en este arzobispado, así en la robustez de sus muros y cubiertas y capillas laterales cuya ampliación resulta de las dos naves menores que ha pocos años se agregaron a esta iglesia...” ${ }^{32}$.

Sin embargo, junto a esta suntuosidad reiteró el mal estado en que se encontraba la portada principal y la necesidad que había de hacer otra acorde con la "suntuosidad" del resto del edificio. En el mismo memorial Antonio de Figueroa redacto el proyecto de la portada principal dentro de un gusto plenamente neoclásico. Esta se compondría de dos cuerpos, a saber: el primero, de orden dórico, y formado por cuatro columnas toscana exentas, que sostendrían un entablamento. Y el segundo, jónico, con sus pedestales, basas, capiteles, alquitraves, friso y cornisas "y con la disminución que por regla general pide el primero» ${ }^{33}$. Este segundo cuerpo quedaría rematado con «un frontis» quedando la altura total de la portada «de tres varas o poco más» ${ }^{34}$.

En cuanto al material, Figueroa afirmó que debía ser el pedestal «de piedra sepia de las canteras de Estepa y desde allí hacia arriba de ladrillo cortados los vuelos de limpio... porque si se

28 La utilización de estos elementos clásicos no eran nuevos por parte de Silva pues ya los empleó por ejemplo en la portada principal de la sevillana iglesia de San Roque, realizada entre 1760 y 1764. Falcón Márquez: Pedro de Silva, pp. 72-73.

29 De este artista sabemos que en 1800 estaba avecindado en Morón de la Frontera, para cuya iglesia de San Miguel labró dos pilas de jaspe negro. Villa Nogales: Documentos inéditos, p. 15.

30 Expedientes sobre las necesidades de la obra de La Campana, 1784. AGAS. Justicia 2012. Posiblemente se aprovechó para que este mismo maestro realizara el aguamanil de la sacristía que corresponde a la misma época.

31 Ibidem.

32 Memorial de Antonio de Figueroa, Sevilla, 3 de diciembre de 1792. AGAS, Justicia 2012.

33 Ibidem.

34 Ibidem. 


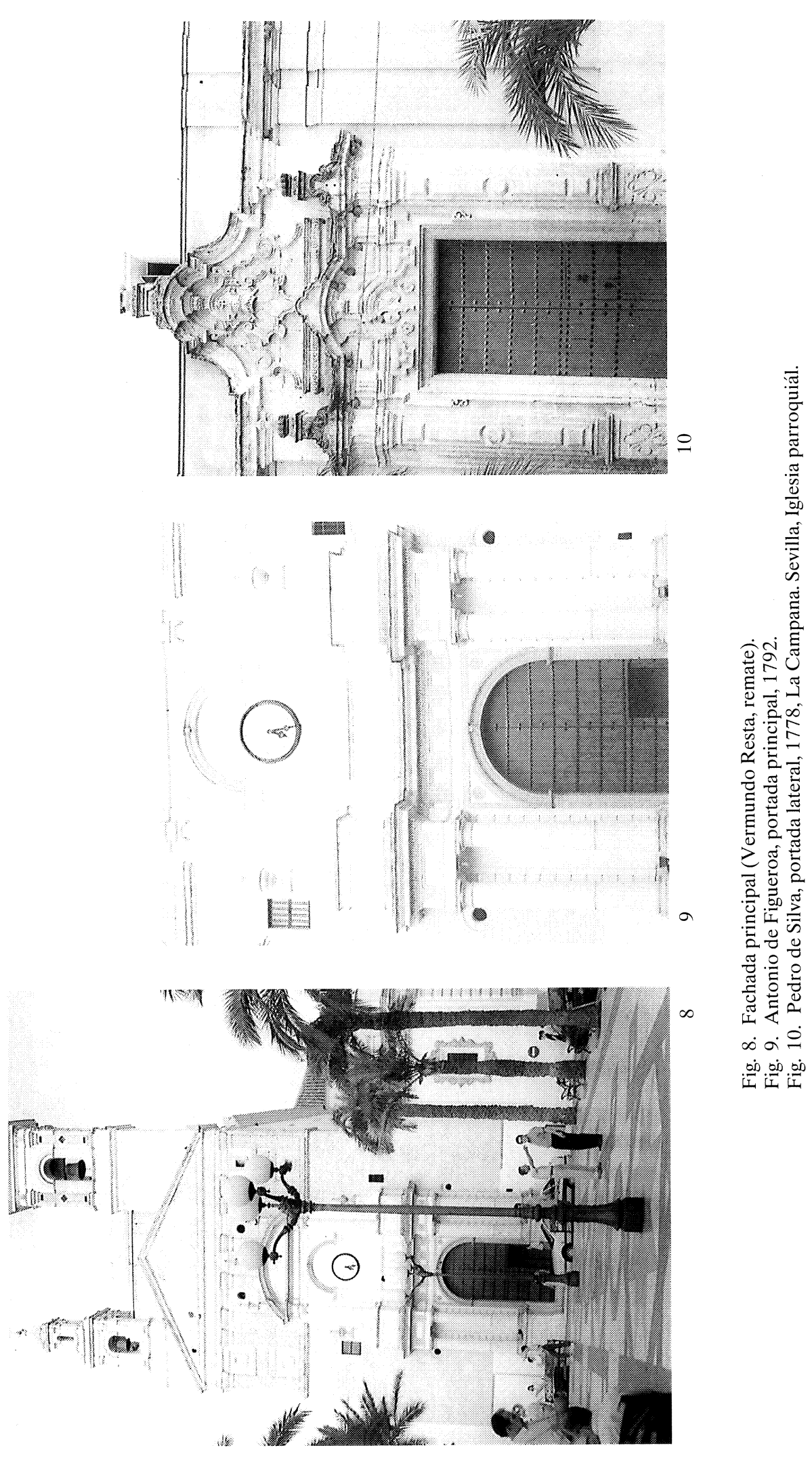


intentara ejecutar toda esta portada de piedra excedería a crecida cantidad...» ${ }^{35}$. El costo total de su construcción fue estimado por el maestro Figueroa en unos 27.657 reales de vellón ${ }^{36}$.

El proyecto de Figueroa fue aprobado por el arzobispado y construida la portada al año siguiente, es decir, en 1793. Sin duda, constituye un buen ejemplo del sobrio arte neoclásico, muy academicista y acorde con los gustos de fines del siglo XviII (Fig. 9).

En el centro del segundo cuerpo está hoy la esfera del reloj donde, en origen, estaba una ventana que daba luz al pasadizo interior. De las dos torres que rematan la fachada hemos de decir que al menos la más grande parece que fue reedificada por Pedro de Silva, pues, la utilización de pilastras en su cuerpo, el colorido de los azulejos y el remate hexagonal tienen cierta semejanza con otras torres proyectadas por este mismo arquitecto, como la de la iglesia de Zufre, o la de San Pedro de Huelva ${ }^{37}$. En su conjunto este frontispicio muestra una superposición de estilos muy característicos del arte español.

Sin duda, Antonio de Figueroa fue un digno continuador del arte de la saga de la familia Figueroa, culminando el arte de su padre Ambrosio en cuyas estructuras barrocas se entreveían ya algunos elementos de lo que iba a ser el nuevo estilo imperante, es decir, el neoclásico. Antonio de Figueroa puede considerarse como la figura clave en el paso del barroco al neoclásico en el arte sevillano.

Esteban Mira Caballos Doctor por la Universidad de Sevilla

\section{A PROPÓSITO DE «EL GRECO OF CRETE»*}

Los estudios sobre El Greco han recibido un notable impulso en los últimos años desde su tierra natal, Creta. Organizado por el prof. Nicos Hadjinicolaou, en septiembre de 1990 se celebró en Heraklion (la Candia de Theotocopoulos) un Simposio Internacional, El Greco of Crete, que estuvo acompañado por la primera gran exposición de obras del pintor celebrada en Grecia. Poco después se creó en Rethymnon «El Greco Centre», adscrito al Institute for Mediterranean Studies - Foundation for Research and Technology, y, ya más recientemente, en septiembre de 1995, se celebraron (también como fruto de la capacidad de organización del prof. Hadjinicolaou) la exposición El Greco in Italy \& Italian Art, en la Pinacoteca Nacional de Atenas, y un nuevo Simposio Internacional con el mismo tema en Rethymnon. Coincidiendo con la celebración de este último evento se produjo la publicación de las actas del Simposio de 1990, un monumental volumen de 650 páginas, cuidadosamente editado y que comprende 43 trabajos debidos a estudiosos de una decena de países de Europa y América. La mayor parte de ellos presentan importantes aportaciones a nuestro conocimiento de la obra de Theotocopuli, de su entorno cultural y artístico y de las repercusiones de su obra en el arte posterior o en la cultura de nues-

35 Ibidem.

36 Ibidem.

37 Conocemos el concierto entre la fábrica de la iglesia y Francisco Matías Solano, «vecino de Sevilla, en Triana, calle de la Cava Nueva, maestro de fundir campanas" para hacer una campana nueva para la torre, pues, la que había se había quebrado. Para ello se le entregó el metal de la campana quebrada que pesó 599 libras. La Campana, 9 de junio de 1689. Archivo de Protocolos de Carmona, escribanía de Francisco Bázquez de Tapia 1686-1694, ff. 74-77v.

* Proceedings of the International Symposium help on the occasion of the 450th anniversary of the artist's birth (Iraklion, Crete, 1-5 September 1990). Ed. por Nicos Hadjinicolaou. Heraklion, Municipality of Iraklion, 1995. 653 pp. 